\section{Response to Tolva et al.}

The Prospective Lynch Syndrome Database (PLSD) is a global repository for clinical data collected during prospective surveillance of individuals who have been shown, on genetic testing, to carry pathogenic variants in one of four mismatch repair (MMR) genes, (path_) MLH1, MSH2, MSH6, or $P M S 2$. Its objectives include determination of the cancer risks and survival associated with these variants in patients under surveillance, assessment of the impact of interventions, and the creation of a shared resource through which ideas on the mechanisms involved in Lynch syndrome can be explored. Through this work, PLSD aims to provide high quality evidence that will be useful to patients and professionals, including those who are involved in developing guidance or recommendations for clinical management, although these are not areas of activity for PLSD itself.

In our recent study published in Genetics in Medicine ${ }^{1}$ we reported cumulative incidences for breast cancer at 75 years of age in female path_MLH1, path_MSH2, path_MSH6, and path_PMS2 carriers, of $12.3 \%, 14.6 \%, 13.7 \%$, and $15.2 \%$, respectively, with approximately $20 \%$ of cancers diagnosed before 50 years of age. Our study did not include a control group. Although these risks are not strikingly different from contemporary risks reported in many countries, Tolva et al. ${ }^{2}$ have compared our raw data for breast cancer with the incidence rates reported for Finland and found that the incidence was higher in PLSD (standardized incidence ratio [SIR] 1.37, 95\% confidence interval $[\mathrm{CI}]=1.08-1.71)$. The PLSD data for each of the Lynch syndrome genes individually did not differ significantly from the population incidence in Finland. Tolva et al. ${ }^{2}$ have also undertaken a meta-analysis of breast cancer incidence in nine recently reported cohort studies in Lynch syndrome, including an earlier and smaller study in PLSD. ${ }^{3}$ Together these nine studies included data on 4898 females and 177 breast cancers. Tolva et al. $^{2}$ found a significantly increased risk of breast cancer in Lynch syndrome (SIR 2.13; 95\% CI $=1.66-2.74$ ) and in $\mathrm{MSH} 2$ carriers alone ( $\mathrm{SIR}=2.27$; 95\% CI 1.28-4.04). These observations contribute to a longstanding debate as to whether breast cancer risks are increased in Lynch syndrome, but a number of methodological issues deserve consideration. In relation to Tolva et al.'s findings in the PLSD data, ${ }^{2}$ only $13.7 \%$ of PLSD patients were recruited in Finland, the country whose general population they used for their comparisons. Similarly, in their meta-analysis Tolva et al. ${ }^{2}$ did not specify whether incidences in Lynch syndrome patients were compared with those in matched country-specific general populations. Moreover, although the cohorts in their meta-analysis were stated by
Tolva et al. $^{2}$ to be independent, we are aware that some patients in the smaller PLSD cohort reported in 2018 by Møller et al. ${ }^{3}$ and included by Tolva et al. ${ }^{2}$ overlapped with those in other cohorts that were included. Tolva et al. ${ }^{2}$ do not present their findings according to the methods used in the studies included in their meta-analysis. It would be helpful to understand, for example, the relative contributions of prospective and retrospective studies to their overall findings.

Although PLSD attempts to minimize bias through its prospective design, biases in ascertainment will inevitably be present. Until the recent and still patchy implementation of comprehensive testing for colorectal cancers by microsatellite instability analysis or mismatch repair protein immunohistochemistry, ${ }^{4}$ genetic testing for Lynch syndrome was undertaken when there was an unusual family history of multiple cancers diagnosed at an early age. This approach is expected to select (albeit inefficiently) not only for pathogenic variants in the mismatch repair genes, but also for pathogenic variants in other cancer predisposition genes that may pose separate risks or impact penetrance and/or expression. Prior to gene panel or genomic tests such variants were usually not tested for and they are still incompletely known and understood. Their frequencies and impact in PLSD are unknown, as at present are the impacts of environmental and lifestyle factors.

Cancer awareness in those having genetic testing and surveillance for Lynch syndrome is likely to be high, but their participation in screening programs, such as those for breast cancer, is unknown. If screened more, these individuals may be more susceptible to overdiagnosis, which is well recognized in breast cancer screening programs ${ }^{5}$ and is also a topic of debate in colorectal cancer in Lynch syndrome. ${ }^{6}$

We welcome the contribution made by Tolva et al., ${ }^{2}$ and invite new collaborators to join PLSD and to use its data to address the many uncertainties that remain in Lynch syndrome.

\section{DISCLOSURE}

The authors declare no conflicts of interest.

Publisher's note Springer Nature remains neutral with regard to jurisdictional claims in published maps and institutional affiliations.

\section{Julian R. Sampson, DM, FMedSci (iD ${ }^{1}$, Mev Dominguez-Valentin, $P h D^{2}$, Toni T. Seppälä, $M D, P h D^{3,4}$ and Pål Møller, $M D^{2,5,6}$}

${ }^{1}$ Institute of Medical Genetics, Division of Cancer and Genetics, Cardiff University School of Medicine, Cardiff, UK; ${ }^{2}$ Department of Tumor Biology, Institute of Cancer Research, The Norwegian Radium Hospital, Oslo University Hospital, Oslo, Norway; ${ }^{3}$ Department of Gastrointestinal Surgery, Helsinki University Central Hospital, Helsinki, Finland; ${ }^{4}$ Clinicum, University of Helsinki, Helsinki, Finland; ${ }^{5}$ Department of Medical Genetics, The Norwegian Radium Hospital, Oslo University Hospital, Oslo, Norway; ${ }^{6}$ Centre for Cancer Cell Reprogamming, University of Oslo, Oslo, Norway. Correspondence: Julian R. Sampson (sampson@cf.ac.uk) 


\section{REFERENCES}

1. Dominguez-Valentin M, Sampson JR, Seppala TT, et al. Cancer risks by gene, age, and gender in 6350 carriers of pathogenic mismatch repair variants: findings from the Prospective Lynch Syndrome Database. Genet Med. 2019 Jul 24; https://doi.org/10.1038/s41436-019-0596-9 [Epub ahead of print].

2. Tolva G, Gandini S, Marabelli M, et al. Correspondence to DominguezValentin $\mathrm{M}$ et al. 2019: Cancer risks by gene, age, and gender in 6350 carriers of pathogenic mismatch repair variants: findings from the Prospective Lynch Syndrome Database. Genet Med (in press).

3. Moller P, Seppala TT, Bernstein I, et al. Cancer risk and survival in path_MMR carriers by gene and gender up to 75 years of age: a report from the Prospective Lynch Syndrome Database. Gut. 2018;67: 1306-1316
4. Shaikh T, Handorf EA, Meyer JE, et al. Mismatch repair deficiency testing in patients with colorectal cancer and nonadherence to testing guidelines in young adults. JAMA Oncol. 2018;4:e173580.

5. Welch HG, Prorok PC, O'Malley AJ, Kramer BS. Breast-cancer tumor size, overdiagnosis, and mammography screening effectiveness. N Engl J Med. 2016:375:1438-1447.

6. Seppala TT, Ahadova A, Dominguez-Valentin M, et al. Lack of association between screening interval and cancer stage in Lynch syndrome may be accounted for by over-diagnosis; a prospective Lynch syndrome database report. Hered Cancer Clin Pract. 2019;17:8.

Advance online publication 5 December 2019. doi:10.1038/s41436-019-0717-5 